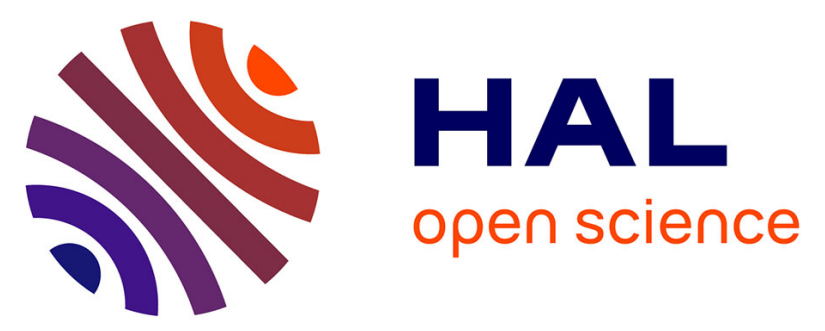

\title{
The inversa type of recessive dystrophic epidermolysis bullosa is caused by specific arginine and glycine substitutions in type VII collagen
}

Peter C van den Akker, Jemima E Mellerio, Anna E Martinez, Lu Liu, Rowdy Meijer, Patricia Jc Dopping-Hepenstal, Anthonie J van Essen, Hans Scheffer, Robert Mw Hofstra, John A Mcgrath, et al.

\section{To cite this version:}

Peter C van den Akker, Jemima E Mellerio, Anna E Martinez, Lu Liu, Rowdy Meijer, et al.. The inversa type of recessive dystrophic epidermolysis bullosa is caused by specific arginine and glycine substitutions in type VII collagen. Journal of Medical Genetics, 2010, 48 (3), pp.160. 10.1136/jmg.2010.082230 . hal-00588661

\section{HAL Id: hal-00588661 \\ https://hal.science/hal-00588661}

Submitted on 26 Apr 2011

HAL is a multi-disciplinary open access archive for the deposit and dissemination of scientific research documents, whether they are published or not. The documents may come from teaching and research institutions in France or abroad, or from public or private research centers.
L'archive ouverte pluridisciplinaire HAL, est destinée au dépôt et à la diffusion de documents scientifiques de niveau recherche, publiés ou non, émanant des établissements d'enseignement et de recherche français ou étrangers, des laboratoires publics ou privés. 
Van den Akker et al.

1 The inversa type of recessive dystrophic epidermolysis bullosa is caused by specific

2 arginine and glycine substitutions in type VII collagen

3

4 Short title: COL7A1 missense mutations in RDEB-I

5

6 Peter C. van den Akker ${ }^{1}$, Jemima E. Mellerio ${ }^{2,3}$, Anna E. Martinez ${ }^{3}$, Lu Liu ${ }^{4}$, Rowdy Meijer ${ }^{5}$,

7 Patricia J.C. Dopping-Hepenstal ${ }^{4}$, Anthonie J. van Essen ${ }^{1}$, Hans Scheffer ${ }^{5}$, Robert M.W.

8 Hofstra $^{1}$, John A. McGrath ${ }^{6}$, Marcel F. Jonkman ${ }^{7}$

9

$10{ }^{1}$ Department of Genetics, University Medical Center Groningen, University of Groningen,

11 Groningen, the Netherlands; ${ }^{2}$ St John's Institute of Dermatology, Guy's and St Thomas'

12 NHS Foundation Trust, London, UK; ${ }^{3}$ Department of Dermatology, Great Ormond Street

13 Hospital NHS Trust, London, UK; ${ }^{4}$ The Robin Eady National Diagnostic Epidermolysis

14 Bullosa Laboratory, GSTS Pathology, St John's Institute of Dermatology, St Thomas'

15 Hospital, London, UK; ${ }^{5}$ Department of Human Genetics, Radboud University Nijmegen

16 Medical Centre, Nijmegen, the Netherlands; ${ }^{6}$ St John's Institute of Dermatology, King's

17 College London (Guy's Campus) and Guy's and St Thomas' NHS Foundation Trust, London,

$18 \mathrm{UK} ;{ }^{7}$ Department of Dermatology, University Medical Center Groningen, University of

19 Groningen, Groningen, the Netherlands

20

21 Corresponding author: Peter C. van den Akker, MD

22 Department of Genetics, University Medical Center Groningen

23 Hanzeplein 1, PO BOX 30.001, 9700 RB Groningen, the Netherlands

24 Tel. +31 50361 7100, fax +31 50361 7230, e-mail p.c.van.den.akker@ medgen.umcg.nl

25 Word count: text 3837. 
Van den Akker et al.

\section{ABSTRACT}

3 Background The inversa type of recessive dystrophic epidermolysis bullosa (RDEB-I) is a

4 rare variant of dystrophic epidermolysis bullosa, characterized by blistering in the body

5 flexures, trunk, and mucosae. The cause of this specific distribution is unknown. So far, $\underline{20}$

6 COL7A1 genotypes have been described in RDEB-I and genotype-phenotype correlations

7 have not been studied extensively. The aim of the study was to gain more insight into the

8 pathophysiology of this intriguing RDEB-I phenotype.

9 Methods We identified 20 Dutch and British RDEB-I patients and full genotypes in 18 of

10 them. We reviewed the literature on RDEB-I genotypes and conducted an extensive

11 genotype-phenotype correlation study for RDEB-I.

12 Results All 20 patients had generalized blistering at birth and during early infancy. In most

13 patients, the age of transition from generalized to inversa distribution was before the age of 4

14 years. We noted a spectrum of disease severity ranging from the mildest 'mucosal only'

15 phenotype to the severest phenotype with limited acral involvement. The $\underline{29}$ genotypes of our

16 RDEB-I patients and those reported in the literature revealed that RDEB-I is associated with

17 specific recessive arginine and glycine substitutions in the triple-helix domain of type VII

18 collagen.

19 Discussion and conclusion Why these specific arginine and glycine substitutions cause the

20 inversa distribution remains unknown. We could not identify clear differences in location and

21 nature of substituting amino acids between these mutations and missense mutations causing

22 other RDEB phenotypes. We hypothesize that the higher skin temperature in the affected

23 areas plays an important role in the pathophysiology of RDEB-I. 
Van den Akker et al.

1 Keywords: recessive dystrophic epidermolysis bullosa, inversa type; genotype-phenotype

2 correlations; type VII collagen; COL7A1

3 
Van den Akker et al.

\section{INTRODUCTION}

2

3 The inversa type of recessive dystrophic epidermolysis bullosa (RDEB-I; OMIM \#226600) is

4 one of the rare variants of dystrophic epidermolysis bullosa.[1] RDEB-I was first described by

5 Prof. T. Gedde-Dahl Jr in 1971 and is characterized by generalized blistering from birth and

6 during early infancy.[2] Later in infancy or childhood, the predilection sites for blistering

7 change and the body flexures, axis and mucous membranes become the predominant sites of

8 blistering.[2,3] Neither the cause of the unusual distribution of blistering in RDEB-I, nor the

9 cause of the "transition" from a generalized to inversa distribution is known. The specific age

10 at which this transition in blistering predilection sites takes place is also not known, but it

11 probably varies between patients. As with the main subtypes of RDEB, there is a large

12 clinical variation between inversa patients.

13 Immunohistochemically, type VII collagen (Col7) is either slightly reduced or

14 normally present in the skin of RDEB-I patients. Anchoring fibrils, which are composed of

15 large numbers of Col7 dimers, can be either reduced or normal in number, and can have a

16 hypoplastic or normal ultrastructural appearance.[4-6] Transient retention of Col7 in basal

17 keratinocytes can be a typical immunohistochemical feature in the early stages.[7]

18 Similar to the other subtypes of DEB, RDEB-I is caused by mutations in the COL7A1

19 gene encoding type VII collagen.[1] However, while genotype-phenotype correlations for the

20 major subtypes of RDEB have been extensively studied in several populations, [1, 8-16] there

21 is little data on genotype-phenotype correlations for RDEB-I. Our study covers the largest

22 RDEB-I cohort reported to date, comprising 20 RDEB-I patients from the Netherlands and the

23 UK. Here we describe this cohort and the genotypes identified in 18 of them, and we discuss

24 the genotype-phenotype correlations identified in these patients and those previously reported

25 in the literature. 
Van den Akker et al.

3 PATIENTS AND METHODS

4

\section{Patients}

6 A diagnosis of DEB was established in a set of 20 patients on the basis of clinical findings,

7 family history, histopathology, immunofluorescence antigen mapping, electron microscopy,

8 and COL7A1 mutation analysis. The diagnosis of RDEB-I was based on the typical clinical

9 findings.[1, 3] All patients were evaluated by the same professionals in the University

10 Medical Center Groningen, the Netherlands (MFJ), Great Ormond Street Hospital for

11 Children or St. Thomas' Hospital, London, UK (JEM, AEM, JAM). Informed consent was

12 given for all skin biopsies and venapunctures, and all studies were approved by the local

13 medical ethical committees (IRB) and conducted in accordance with the guidelines stated in

14 the Declaration of Helsinki.

15

\section{Immunofluorescence and electron microscopy studies}

17 For immunofluorescence studies (IF), $4 \mathrm{~mm}$ punch biopsies of rubbed perilesional skin and/or unaffected skin from non-predilection sites (i.e. the ventral side of the upper arm) were obtained from patients 1-6 and 16 and snap frozen. Four or five $\mu$ m thick cryostat sections were prepared and the amount of Col7 was determined using monoclonal antibody LH7:2 as

21 previously described.[14, 17, 18] For electron microscopy, $2 \mathrm{~mm}$ punch biopsies were taken

22 from the same locations from the same patients and prepared and analyzed as previously 23 described. 
Van den Akker et al.

\section{$1 \quad$ COL7A1 mutation analysis}

2 The COL7Al gene was fully analyzed for pathological mutations either by complete

3 sequencing or by pre-screening using either Denaturing Gradient Gel Electrophoresis or

4 Conformation-sensitive Capillary Electrophoresis followed by targeted sequencing as

5 described previously.[14, 19] Genomic DNA was extracted from peripheral leukocytes.

6

7

8 RESULTS

9

\section{Clinical characteristics}

11 In total, we identified 20 patients with RDEB-I, six from the Netherlands (patients 1-6) and

1214 from the UK (patients 7-20). Clinical characteristics are listed in supplemental Table S1

13 and Figure 1. Patients 1 and 2 are sister and brother; patient 14 reported two similarly affected

14 sibs, but they are not known in our clinics; no other patients had any siblings affected with

15 DEB. Eighteen patients $(90 \%)$ presented with generalized blistering and skin erosions at birth or shortly after and during early infancy; in one the onset of blistering was within the first six months and in another it was unknown. Seven (35\%) had congenital localized absence of skin (CLAS), mostly on the lower legs/ankles/feet, which remained fragile during life. With age, blistering on the extremities decreased markedly in most patients and became more restricted to the body trunk and folds. The most frequently affected skin areas were the proximal body flexures, i.e. the axillae and groins, and the body axis, i.e. the back, neck and buttocks symmetrically. None of the patients had involvement of the acra as the dominant feature. In fact, even after trauma most patients only occasionally experienced blistering of hands and feet, and none of them developed 'mitten deformities' as seen in the 'severe generalized' RDEB (RDEB-sev gen) subtype. However, four patients $(3,9,19,20)$ had more extensive 
Van den Akker et al.

1 blistering of the acra and developed mild pseudosyndactyly in one of the interdigital web

2 spaces. In contrast, in four patients $(7,13,15,16)$ skin blistering nearly ceased completely

3 after infancy and they only had mucosal involvement and nail dystrophy.

In 6/20 (30\%) patients, lesions of the oral mucosa were already present at birth,

5 whereas in the other patients the oral mucosa became affected from infancy onwards (Table

6 S1). When the RDEB-I phenotype had established, all patients had severe mucosal

7 involvement, mostly affecting the oral cavity, oesophagus and anus. In $6 / 10$ (60\%) women the

8 genital skin and mucosa were affected, and in one this severely complicated healing after

9 childbirth. Swallowing difficulty or dysphagia was reported in 17/20 (85\%) patients. Twelve

10 patients $(60 \%)$ had proven oesophageal strictures and $10(50 \%)$ needed repeated oesophageal

11 dilatations; patient 5 received more than 150 dilatations before the age of 30 . Ankyloglossia

12 and microstomia due to scarring of the oral mucosa were present in $15(75 \%)$ and $13(65 \%)$

13 patients, respectively, and was noted as early as 6 years of age (patient 15). Blistering of the

14 external auditory canal was seen in 7/20 (35\%) patients, which was complicated by narrowing

15 of the canal in three, and subsequent conductive hearing loss after the age of 30 in two (10\%).

16 None of the patients were growth retarded, had renal failure or developed squamous cell

17 carcinomas. Patients 10, 12, 15, and 20 had anaemic periods and patient 12 required

18 intermittent blood transfusions. Constipation was an almost invariable feature, although only

19 in part due to anal blistering.

21 Transition age

22 The age of transition of blistering from extremities to body axis and flexures was reported in

$2313 / 20$ patients and ranged from one to 18 years. In nine patients, transition was reported

24 between birth and age four years. Patient 6 was the only one in whom the transition age could

25 be objectively determined. He was diagnosed with probable recessive bullous dermolysis of 
Van den Akker et al.

1 the newborn, since his generalized blisters present at birth disappeared within the first few

2 months, and the immunofluorescence biopsy revealed Col7 retention in basal keratinocytes.

3 However, towards the end of his first year, blistering activity increased on the trunk, axillae,

4 intraorally and especially in the diaper area. Hence, transition age was before the end of the

5 first year.

6

\section{Immunofluorescence and electron microscopy findings}

8 Immunofluorescence studies on healthy skin from non-predilection sites revealed normal

9 Col7 in patients $3,4,6,16$, and reduced $\mathrm{Col} 7$ in patient 1 . Retention of Col7 was noted in

10 basal keratinocytes of patient 3 (aged 33) and patient 6, in whose skin both small and large

11 Col7 positive granules were seen at the age of 1 month. Basal keratinocytes of a peri-lesional

12 skin biopsy of patient 2, obtained a few days after birth, also revealed Col7 retention. Peri-

13 lesional skin from patient 5 revealed reduced Col7. Electron microscopy studies revealed

14 slightly hypoplastic anchoring fibrils in normal (patient 4) or reduced numbers (patients 3, 6,

15 16) at non-predilection sites. Electron microscopy studies of affected skin revealed a reduced

16 number of abnormal or rudimentary anchoring fibrils in patients $1,2,3,4,5$, and 16. Col7-

17 containing vesicles were seen in the rough endoplasmic reticulum in patient 2.

19 Genotypes and genotype-phenotype correlations

20 Genotypes were available for 18 of our 20 RDEB-I patients. The genotypes of patients 1-5

21 have been reported previously.[14] Table 1 lists the $\underline{29}$ full genotypes associated with RDEB-I

22 identified in this study and the literature. 
Van den Akker et al.

1 Table 1. Genotypes of RDEB-inversa patients reported in this study and in the literature.

\begin{tabular}{|c|c|c|c|c|c|c|c|c|c|c|c|c|}
\hline No. & $\begin{array}{l}\text { Mutation 1 }{ }^{1} \\
\text { Nucleotide }\end{array}$ & Amino acid & Exon & Consequence $^{2}$ & Domain $^{3}$ & $\begin{array}{l}\text { Mutation 2 }^{1} \\
\text { Nucleotide }^{4}\end{array}$ & Amino acid & Exon $^{5}$ & Consequence $^{2}$ & Domain $^{3}$ & Patients & Reference \\
\hline 1 & c. $4039 \mathrm{G}>\mathrm{T}$ & p.Gly1347Trp & 34 & Missense & THD & c.8540insC & p.Glu2848X & 116 & PTC & $\mathrm{NC} 2$ & Pat 16 & This study \\
\hline 2 & c. $4945 C>G$ & p.Gly1649Arg & 53 & Missense & THD & $\mathrm{NF}^{6}$ & & & & & Pat 13 & This study \\
\hline 3 & c.5282G $>C$ & p.Gly1761Ala & 60 & Missense & THD & c. $5282 \mathrm{G}>\mathrm{C}$ & p.Gly1761 Ala & 60 & Missense & THD & Pat 6 & This study \\
\hline 4 & c. $5720 \mathrm{G}>\mathrm{A}$ & p.Gly1907Glu & 68 & Missense & THD & c. $7805 \mathrm{G}>\mathrm{A}$ & p.Gly2602Glu & 105 & Missense & THD & Pat 3 & [14] \\
\hline 5 & $\begin{array}{l}\text { c.5720_5721 } \\
\text { GA>AT }\end{array}$ & p.Gly1907Asp & 68 & Missense & THD & c. $4018 \mathrm{C}>\mathrm{T}$ & p.Arg1340X & 34 & PTC & THD & $2 \mathrm{x}$ & [26] \\
\hline 6 & $\begin{array}{l}\text { c.5720_5721 } \\
\text { GA>AT }\end{array}$ & p.Gly1907Asp & 68 & Missense & THD & c.5047C $>\mathrm{T}$ & p.Arg1687X & 54 & PTC & THD & $\begin{array}{l}\text { Pat 12, } \\
17\end{array}$ & This study \\
\hline 7 & c. $6022 \mathrm{C}>\mathrm{G}$ & p.Arg2008Gly & 73 & Missense & THD & c. $6022 \mathrm{C}>\mathrm{G}$ & p.Arg2008Gly & 73 & Missense & THD & $2 \mathrm{x}$ & {$[20,21]$} \\
\hline 8 & c. $6187 \mathrm{C}>\mathrm{G}$ & p.Arg2063Gly & 74 & Missense & THD & c. $706 \mathrm{C}>\mathrm{T}$ & p.Arg236X & 6 & PTC & $\mathrm{NC} 1$ & $1 \mathrm{x}$ & {$[8]$} \\
\hline 9 & c. $6205 \mathrm{C}>\mathrm{T}$ & p.Arg2069Cys & 74 & Missense & THD & c. $425 \mathrm{~A}>\mathrm{G}$ & p.Lys142Arg & 3 & Splice $\rightarrow$ PTC & $\mathrm{NC} 1$ & $3 \mathrm{x}$ & {$[20,24]$} \\
\hline 10 & c. $6205 \mathrm{C}>\mathrm{T}$ & p.Arg2069Cys & 74 & Missense & THD & c. $3551-3 \mathrm{~T}>\mathrm{G}$ & & IVS26 & Splice $\rightarrow$ PTC & $\mathrm{NC} 1$ & Pat 5 & [14] \\
\hline 11 & c. $6205 \mathrm{C}>\mathrm{T}$ & p.Arg2069Cys & 74 & Missense & THD & c. $3894+1 \mathrm{G}>\mathrm{A}$ & & IVS30 & Splice $\rightarrow$ PTC & THD & $1 \mathrm{x}$ & [16] \\
\hline 12 & c. $6205 \mathrm{C}>\mathrm{T}$ & p.Arg2069Cys & 74 & Missense & THD & c. $3895-1 \mathrm{G}>\mathrm{A}$ & & IVS30 & Splice $\rightarrow$ PTC & THD & $1 \mathrm{x}$ & {$[25]$} \\
\hline 13 & c. $6205 \mathrm{C}>\mathrm{T}$ & p.Arg2069Cys & 74 & Missense & THD & c. $4018 \mathrm{C}>\mathrm{T}$ & p.Arg1340X & 34 & PTC & THD & $1 \mathrm{x}$ & [16] \\
\hline 14 & c. $6205 \mathrm{C}>\mathrm{T}$ & p.Arg2069Cys & 74 & Missense & THD & c. $4027 \mathrm{C}>\mathrm{T}$ & p.Arg1343X & 34 & PTC & THD & $1 \mathrm{x}$ & {$[16]$} \\
\hline 15 & c. $6205 \mathrm{C}>\mathrm{T}$ & p.Arg2069Cys & 74 & Missense & THD & c.5662insG & p.Pro1888AlafsX27 & 67 & PTC & THD & Pat 11 & This Study \\
\hline 16 & c. $6205 \mathrm{C}>\mathrm{T}$ & p.Arg2069Cys & 74 & Missense & THD & c. $6205 \mathrm{C}>\mathrm{T}$ & p.Arg2069Cys & 74 & Missense & THD & $\begin{array}{l}3 \times \text { (pat } \\
4,8,18)\end{array}$ & This study, [14] \\
\hline 17 & c. $6262 \mathrm{G}>\mathrm{A}$ & p.Gly2088Arg & 75 & Missense & THD & c. $676 \mathrm{C}>\mathrm{T}$ & p.Arg226X & 5 & PTC & NC1 & $1 \mathrm{x}$ & {$[26]$} \\
\hline 18 & c. $6637 \mathrm{G}>\mathrm{A}$ & p.Gly2213Arg & 83 & Missense & THD & c.4918delG & p.Gly1640ValfsX70 & 52 & PTC & THD & Pat 9 & This study \\
\hline 19 & c.6815G $>C$ & p.Gly2272Ala & 86 & Missense & THD & c.1363G > T & p.GIn455X & 11 & PTC & $\mathrm{NC1}$ & Pat 15 & This study \\
\hline 20 & c. $7415 \mathrm{G}>\mathrm{A}$ & p.Gly2472Asp & 97 & Missense & THD & c.1874delGT & p.Ser625ArgfsX5 & 14 & PTC & $\mathrm{NC} 1$ & $1 \mathrm{x}$ & {$[26]$} \\
\hline 21 & c. $7864 \mathrm{C}>\mathrm{T}$ & p.Arg2622Trp & 105 & Missense & THD & c. $553 \mathrm{C}>\mathrm{T}$ & p.Arg185X & 5 & PTC & $\mathrm{NC} 1$ & $1 \mathrm{x}$ & [15] \\
\hline 22 & c.7864C>T & p.Arg2622Trp & 105 & Missense & THD & c.2482delCT & p.Ser828CysfsX37 & 19 & PTC & $\mathrm{NC1}$ & $1 \mathrm{x}$ & [9] \\
\hline 23 & c. $7882 \mathrm{C}>\mathrm{T}$ & p.Arg2628Trp & 106 & Missense & THD & c. $1332 \mathrm{C}>\mathrm{A}$ & p.Tyr444X & 10 & PTC & $\mathrm{NC1}$ & $1 \mathrm{x}$ & {$[26]$} \\
\hline 24 & c. $8065 \mathrm{G}>\mathrm{A}$ & p.Gly2689Arg & 109 & Missense & THD & c. $1732 \mathrm{C}>\mathrm{T}$ & p.Arg578X & 13 & PTC & $\mathrm{NC1}$ & Pat 7 & This study \\
\hline 25 & c. $8065 \mathrm{G}>\mathrm{C}$ & p.Gly2689Arg & 109 & Missense & THD & c.6527insC & p.Gly2177TrpfsX113 & 80 & PTC & THD & $1 \mathrm{x}$ & [10] \\
\hline 26 & c. $8083 \mathrm{G}>\mathrm{A}$ & p.Gly2695Ser & 109 & Missense & THD & c. $8083 \mathrm{G}>\mathrm{A}$ & p.Gly2695Ser & 109 & Missense & THD & Pat 1,2 & {$[12,14,22]$} \\
\hline 27 & c. $8156 \mathrm{G}>\mathrm{C}$ & p.Gly2719Ala & 110 & Missense & THD & c.2051-1G>C & & IVS15 & Splice $\rightarrow$ PTC & NC1 & Pat 19 & This study \\
\hline 28 & c. $8323 \mathrm{G}>\mathrm{A}$ & p.Gly2775Ser & 112 & Missense & THD & c. $425 \mathrm{~A}>\mathrm{G}$ & p.Lys142Arg & 3 & Splice $\rightarrow$ PTC & $\mathrm{NC1}$ & $\begin{array}{l}2 \mathrm{x} \text { (pat } \\
14)\end{array}$ & This study, [23] \\
\hline 29 & c. $8323 \mathrm{G}>\mathrm{A}$ & p.Gly2775Ser & 112 & Missense & THD & c. $8323 \mathrm{G}>\mathrm{A}$ & p.Gly2775Ser & 112 & Missense & THD & $1 \mathrm{x}$ & {$[26]$} \\
\hline
\end{tabular}

2 In bold novel COL7A1 mutations.

$3 \quad{ }^{2}$ PTC, premature termination codon; splice $\rightarrow$ PTC, splice site affecting mutation resulting in PTC. 
Van den Akker et al.

$1{ }^{3}$ THD, triple-helix domain; $\mathrm{NC} 1$, non-collagenous 1 domain; $\mathrm{NC} 2$, non-collagenous 2 domain.

$2{ }^{4} \mathrm{NF}$, not found; NA, not available.

$3 \quad{ }^{5}$ IVS, intervening sequences (i.e. introns)

$4{ }^{6}$ Only a single mutation could be identified despite complete sequencing of the other allele. 
Van den Akker et al.

$1 \quad \underline{\text { Six }}$ genotypes consist of homozygous or compound heterozygous missense mutations within

2 the triple-helix domain (THD) of Col7. Twenty-three genotypes are composed of THD

3 missense mutations combined with mutations generating a premature truncation codon (PTC)

4 or an unidentified second mutation (pat 13). Since PTC mutations are generally considered to

5 result in no functional protein, the functional genotype in these patients is determined by the

6 hemizygous missense mutation.[27] Hence, the functional genotype in RDEB-I is that of a

7 homozygous, compound heterozygous or hemizygous missense mutation within the THD.

8 To date, 19 missense mutations have been associated with RDEB-I, all of which are

9 either substitutions of an arginine $(\mathrm{ASs}, \mathrm{n}=\underline{5})$ or a glycine $(\mathrm{GSs}, \mathrm{n}=\underline{14})$ (Table 1, Fig. 2).

10 The $\underline{14}$ GSs are located at $\underline{13}$ different glycine codons. None of the carrier parents were

11 affected, indicating that the mutations are recessive. The question is whether these recessive

12 ASs or GSs are specific for RDEB-I or whether they can also cause other (R)DEB subtypes.

13 Of the five ASs, the p.Arg2063Gly, p.Arg2622Trp, and p.Arg2628Trp mutations have been

14 exclusively reported in RDEB-I, whereas the p.Arg2008Gly and p.Arg2069Cys mutations

15 were also found in non-inversa RDEB subtypes (Table S2). Nine of the 14 recessive GSs have

16 been exclusively reported in RDEB-I, whereas four GSs were also reported in non-inversa

17 RDEB subtypes and the p.Gly2213Arg mutation was reported as a dominant GS (Table S3).

18 Supplementary tables S2 and S3, and Fig. 2 show detailed information about the ASs and GSs.

19 To check whether ASs in general might cause the RDEB-I phenotype, we studied the

20 phenotypes of patients carrying other ASs. The THD of Col7 contains a total of 94 arginines

21 in Gly-X-Y repeats, [35] of which 12 have been found substituted in DEB (HGMD

22 professional database, www.hgmd.org, and unpublished data (HS), 26 August 2010).

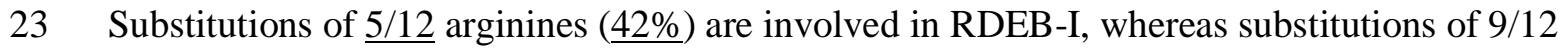

24 arginines $(\underline{75 \%})$ are involved in other DEB phenotypes. Hence, it seems unlikely that ASs are

25 in general the cause of RDEB-I. 
Van den Akker et al.

\section{DISCUSSION}

4

5 The cause of the typical 'inverse' distribution of blistering in RDEB-I is not well understood.

6 We identified 20 Dutch and UK RDEB-I patients and expanded the list of known RDEB-I

7 genotypes from the literature with nine new genotypes, which enabled us to conduct an

8 extensive genotype-phenotype correlation study in RDEB-I. Our results suggest that RDEB-I

9 is caused by a set of specific recessive arginine and glycine substitutions within the THD of

10 Col7.

\section{Clinical characteristics}

13 All 20 patients displayed the typical inversa distribution of skin blistering in the proximal

14 body flexures and the body axis. Mucosal involvement, especially of the oral mucosa, was

15 present in all patients. Nearly all patients started with generalized blistering and a third had congenital localized absence of skin. The age of transition from generalized to inversa

17 distribution took place before the age of 4 years in most patients, but ranged from 1 to 18

18 years. Marked clinical variation was noted between patients and the clinical severity of

19 RDEB-I seems to cover a spectrum, as seen in other DEB phenotypes.[1] Four patients had

20 'mucosal only' RDEB-I in which the mucosal involvement dominated, including severe

21 oesophageal stenosis requiring multiple dilatations, but skin blistering was almost absent. A

22 similar phenotype has been described previously, [10, 23, 36] but was not considered to be

23 within the RDEB-I spectrum due to absence of typical blistering in the body flexures. We

24 think that patients with 'mucosal only' RDEB form the mildest end of the inversa spectrum

25 (with regard to the skin), because the severe mucosal involvement is not part of the milder 
Van den Akker et al.

1 forms of RDEB-O.[1, 14] On the other end of the RDEB-I spectrum, four patients had

2 significant involvement of the acra, leading to mild flexion contractures and limited

3 pseudosyndactyly. This end of the RDEB-I spectrum might be difficult to distinguish from

4 RDEB-O or even RDEB-sev gen.[5, 37] However, these RDEB-I patients were not growth

5 retarded and none had developed squamous cell carcinoma.

A diagnosis of RDEB-I has important implications for the patient and clinician,

7 especially when skin blistering is relatively mild. Nearly all patients have severe oral and

8 oesophageal blistering resulting in intra-oral scarring, microstomia, ankyloglossia, and

9 oesophageal strictures often requiring repeated dilatations. This can result in decreased food

10 intake, poor dental hygiene and oral infections, which warrant careful follow-up of growth

11 and weight and aggressive dental care. Peri-anal blistering commonly results in constipation

12 that should be asked about carefully and treated if present. In women, genital blistering and

13 scarring can interfere with sexual function, complicate vaginal delivery and recovery

14 afterwards, which may be a reason for elective caesarean section. Moreover, blistering of the

15 external auditory canal may lead to conductive hearing loss, requiring hearing aids after the

16 age of 30. Careful inspection and follow-up of the auditory canals is thus warranted and

17 audiologic evaluation may be indicated at later ages.

\section{Genotype-phenotype correlations}

20 The 29 functional genotypes of our 18 RDEB-I patients and those reported in the literature

21 consist of homozygous, compound heterozygous or hemizygous (i.e. in conjunction with a

22 PTC) recessive ASs or GSs within the THD of Col7. To date, five recessive ASs and $\underline{14}$

23 recessive GSs have been associated with RDEB-I. The collagenous THD domain is composed

24 of many consecutive Gly-X-Y triplets that form a triple-helix.[35] These Gly-X-Y repeat

25 sequences are separated into 20 collagenous subdomains (COL1-20) by 19 interruptions or 
Van den Akker et al.

1 imperfections (IM1-19) that provide flexibility to the protein. The largest imperfection, the

2 hinge (IM10), is composed of 39 amino acids and divides the THD into amino (COL1-10)

3 and carboxyl (COL11-20) regions. The glycine residues are located at the centre of the triple-

4 helix and are essential for stable triple-helix formation, whereas the amino acids at the $\mathrm{X}$ and

5 Y positions are exposed on the helix surface and are less essential for triple-helix stability.[38,

6 39] Substitutions of glycine residues therefore have major disruptive effects on triple-helix

7 folding and/or stability, whereas substitutions of $\mathrm{X}$ and $\mathrm{Y}$ residues not necessarily exert

8 pathogenic effects. Therefore, pathogenicity of the GSs identified in RDEB-I was not

9 surprising. Pathogenicity of the RDEB-I ASs was also likely, as they are located at highly

10 conserved positions within Col7.

11 Two RDEB-I ASs and five GSs have also been found in patients with phenotypes

12 other than RDEB-I. This observation suggests that some arginine and glycine codons have the

13 potential to result in RDEB-I when mutated, but other as yet unidentified factors determine

14 the resultant clinical phenotype, which can be RDEB-I or sometimes other. The puzzling

15 question remains as to why some specific arginine and glycine codons possess this potential

16 to induce RDEB-I when mutated, since ASs and GSs in general cause phenotypes other than

17 RDEB-I.[28] We therefore looked more closely into the position of the arginine and glycine

18 codons in the THD and into the nature of the substituting amino acids.

20 The arginine substitutions

21 The five arginine codons are located in collagenous subdomains in the carboxyl region of the

22 THD, of which three in the first two subdomains after the hinge region (Fig. 2, Table S2). The

23 position of the arginine within the Gly-X-Y triplet does not differ from arginines involved in

24 other phenotypes: the five RDEB-I arginines reside in the Y position as do 7 of 9 arginines

25 involved in other DEB subtypes. 
Van den Akker et al.

$1 \quad$ Our findings suggest that for each of the five arginines there is only a specific

2 substitution that can lead to RDEB-I (Tables S2). The arginine at codon 2063 was found

3 substituted by glycine in RDEB-I, whereas substituted by tryptophan in other RDEB

4 phenotypes; the arginine at codon 2622 was found substituted by tryptophan in RDEB-I,

5 whereas substituted by glutamine in RDEB-HS. The p.Arg2008Gly mutation was found

6 homozygously in RDEB-I, whereas substitution of this arginine by cysteine or histidine was

7 reported in other RDEB subtypes. Of note, the p.Arg2008Gly mutation was also found

8 homozygously in a single RDEB-HS patient, emphasizing that the COL7A1 mutation is not

9 the only factor determining the inversa phenotype. On the other hand, the p.Arg2069Cys

10 mutation was not only found in $\underline{12}$ inversa patients, but also in four with RDEB-O. However,

11 it cannot be excluded that these patients will ultimately develop the RDEB-I phenotype, as it

12 can take years for the inversa phenotype to become evident. Therefore, the p.Arg2069Cys is

13 the most frequently observed RDEB-I mutation and can be considered specific for RDEB-I.

14 The specific substituting amino acids leading to RDEB-I, however, are different for

15 each arginine codon and from chemically different groups (Table S2). At codons 2008, 2063

16 and 2069, the large, hydrophilic arginine is substituted by the smaller, nonpolar residues,

17 glycine or cysteine, whereas at codons 2622 and 2628 the arginine is substituted by the large,

18 hydrophobic and aromatic tryptophan. The same substituting amino acids have been found to

19 replace other arginines in the THD in non-inversa phenotypes (Fig 2). This emphasizes that

20 there is not a specific type of amino acid that leads to RDEB-I when replacing an arginine, but

21 it is the combination of a specific substituting amino acid at a specific arginine codon position.

22 Interestingly, the arginine codons 2622 and 2628 in COL19 are located close to the cysteine

23 residue at position 2634. This is the only cysteine residue in the THD and might be involved

24 in disulfide binding with the non-collagenous domain of a pairing Col7 molecule.[35] 
Van den Akker et al.

1 Substituting either arginine 2622 or 2628 could therefore lead to instable Col7 dimers as a

2 result of local conformational changes.

3

4 The glycine substitutions

5 All 13 glycine codons associated with RDEB-I are located in collagenous subdomains of the

6 THD (Fig. 2, Table S3). Four of $\underline{13}(\underline{31} \%)$ glycine codons are located in subdomain COL19.

7 This number is surprisingly high, even though COL19 is the largest subdomain, containing

8 almost $16 \%$ of Gly-X-Y repeats. These four GSs, as well as p.Gly2775Ser in COL20 are

9 located close to the carboxyl end of the THD. Additionally, the p.Gly1347Trp mutation in the

10 COL2 subdomain is located near the amino end of the THD and glycine codon 1907 (COL10)

11 is located near the hinge region, the end of the amino region of the THD. It can thus be

12 speculated that GSs located at either end of the amino and carboxyl regions of the THD can

13 cause the relatively mild RDEB-I phenotype. This agrees with the finding that GSs near the

14 ends of the THD cause less severe triple-helix destabilization than central GSs and

15 concordantly lead to less severe disease.[23] Interestingly, the amino acids replacing the

16 glycines are either chemically very different and destabilizing, or chemically quite similar and

17 less destabilizing.[38]

18 Recently, Chiaverini et al. suggested that GSs located near the borders of collagenous

19 subdomains exert different, i.e. milder, pathogenic effects than GSs located in the centre of

20 collagenous subdomains and consequently result in RDEB-I.[26] However, the combined

21 genotypic data of our RDEB-I patients and those reported in the literature show that of the 13

22 glycine codons involved in RDEB-I only 6/13 (46\%) are located in the first three or last three

23 Gly-X-Y triplets of their respective collagenous subdomain. The other 7/13 (54\%) are located

24 in the central portion of the subdomain (Table S3). Hence, a GSs location near the border of a 
Van den Akker et al.

1 collagenous subdomain might predispose to RDEB-I, but it is certainly not the only factor,

2 since specific central GSs also have the potential to induce RDEB-I.

3 There were no differences in the location of the glycine codons or the nature of the

4 substituting amino acids between GSs causing the 'mucosal only' phenotype and the

5 phenotype with limited acral involvement (Tables 1 and S3). However, the four glycine

6 codons involved in RDEB-I with limited acral involvement have been reported in the RDEB-

7 sev gen or DDEB phenotypes. In contrast, of the glycine codons involved in the RDEB-I

8 'mucosal only' phenotype only glycine codon 1347 was reported in other, milder RDEB

9 phenotypes.[10, 30, 32]

\section{Putative temperature related pathophysiology in RDEB-I}

12 Because the lesions in RDEB-I are mainly restricted to body locations where skin

13 temperatures are the highest (Fig. 3),[40, 41] we hypothesize that the pathophysiology in

14 RDEB-I is temperature-dependent. Kern et al. showed by in vitro experiments that Col7

15 homotrimers from a 'mucosal only' patient (genotype 18, Table 1) dissociated at lower

16 temperatures $\left(\mathrm{Tm}=33-35^{\circ} \mathrm{C}\right)$ compared to normal $\mathrm{Col} 7\left(\mathrm{Tm}=39-41^{\circ} \mathrm{C}\right) \cdot[10]$ Moreover,

17 Fritsch et al. showed that Col7 trimers harbouring three different dominant GSs in the THD

18 had even more reduced thermostability ( $\operatorname{Tm} 20-33^{\circ} \mathrm{C}$, mono-expression).[39] Furthermore,

19 four GSs in the THD of type XVII collagen also reduced the thermostability of recombinant

20 proteins.[42] This reduced thermostability reflects folding defects of procollagen molecules

21 into Col7 trimers and/or packing defects of Col7 trimers into anchoring fibrils. The lower

22 dissociation temperatures of Col7 homotrimers harbouring the dominant GSs suggest that

23 dominant GSs have more dramatic destabilizing effects on Col7 than recessive GSs. Hence,

24 we speculate that the recessive GSs found in RDEB-I only slightly lower the temperature

25 dissociation thresholds for Col7 homotrimers. The only body regions where skin temperatures 
Van den Akker et al.

1 are continuously high enough to cross these temperature thresholds are the inversa regions.

2 This leads to increased Col7 destabilization with subsequent blistering only in these body

3 regions and not on the more distal body parts where skin temperatures are generally lower.

4 The invariable involvement of the oral mucosa and oesophageal involvement in most patients

5 supports this hypothesis. Temperature-dependent pathophysiology has been shown for

6 bathing suit ichthyosis (BSI), in which skin distribution is quite similar to RDEB-I.[41]

7 Moreover, also in BSI the skin features are more severe in infancy than later on. In BSI,

8 specific mutations in the transglutaminase-1 gene, TGM1, lead to decreased enzyme activity

9 at temperatures above $33^{\circ} \mathrm{C},[43]$ explaining the 'inversa-like' skin distribution. Interestingly,

10 most BSI causing TGM1 mutations found to date are arginine substitutions.[44] The ASs

11 found in RDEB-I could thus exert the same effects as the GSs. A temperature-dependent

12 effect in skin disorders has also been noted for mutations in the TYR and CDKN2A genes.[45,

13 46] Temperature-dependent pathophysiology could also explain the transition from

14 generalized to inversa distribution, as one can assume that skin temperature in utero will be

15 higher than postnatally in all body regions. An obvious question is whether patients have

16 more severe blistering during warmer circumstances, but this was denied by all patients.

17 Hence, the temperature hypothesis is an interesting topic for future studies.

19 Conclusion and clinical implications

20 Our results suggest that RDEB-I is caused by specific recessive arginine and glycine

21 substitutions in the THD of Col7. The p.Arg2069Cys mutation is the most frequently

22 observed RDEB-I mutation. This study provides detailed insights into genotype-phenotype

23 correlations in RDEB-I, which is a first step towards understanding the pathophysiology of

24 the typical inverse distribution in this rare RDEB subtype. The exact mechanisms by which 
Van den Akker et al.

1 these ASs and GSs cause RDEB-I are not yet understood, but we hypothesize that the

2 pathophysiology of the inversa distribution is temperature-dependent.

3 These findings have important implications for the diagnosis and prognosis in DEB,

4 since the identification of one of the specific ASs or GSs as the only functional allele in a

5 newborn with DEB is predictive of the future development of RDEB-I. However, a phenotype

6 with more severe skin involvement may occasionally develop due to currently unknown

7 genetic, epigenetic or non-genetic modifiers.

8

9

10

11

12

None.

\section{ACKNOWLEDGEMENTS}

We would like to thank the patients and their parents for their cooperation and Jackie Senior for editing the manuscript. This study was supported by the Netherlands Organization for Health Research and Development (ZonMw) grant 92003541, the Prof. J.P. Nater Foundation and the Vlinderkind (Dutch Butterfly) Foundation. JEM and JAM acknowledge financial support from the Department of Health via the National Institute for Health Research (NIHR) comprehensive Biomedical Research Centre award to Guy's and St Thomas' NHS Foundation Trust in partnership with King's College London and King's College Hospital NHS Foundation Trust. 
Van den Akker et al.

1

2 COPYRIGHT LICENSE STATEMENT / LICENCE FOR PUBLICATION

3

4 The Corresponding Author has the right to grant on behalf of all authors and does grant on

5 behalf of all authors, an exclusive licence on a worldwide basis to the BMJ Publishing Group

6 Ltd, and its Licensees to permit this article (if accepted) to be published in the Journal of

7 Medical Genetics and any other BMJPGL products and sublicenses such use and exploit all

8 subsidiary rights, as set out in our licence

9 (http://group.bmj.com/products/journals/instructions-for-authors/licence-forms).

10

11

12 PATIENT CONSENT

13

14 We obtained written consent for publication of all patient images. 
Van den Akker et al.

\section{REFERENCES}

2

31 Fine JD, Eady RA, Bauer EA, Bauer JW, Bruckner-Tuderman L, Heagerty A, Hintner H,

4 Hovnanian A, Jonkman MF, Leigh I, McGrath JA, Mellerio JE, Murrell DF, Shimizu H,

5 Uitto J, Vahlquist A, Woodley D, Zambruno G. The classification of inherited

6 epidermolysis bullosa (EB): Report of the Third International Consensus Meeting on

7 Diagnosis and Classification of EB. J Am Acad Dermatol 2008;58:931-50.

82 Gedde-Dahl Jr T. Epidermolysis Bullosa: A clinical, genetic and epidemiological study.

9 Universitetsforlaget (Oslo), 1970. Baltimore: The Johns Hopkins Press; 1971.

103 Anton-Lamprecht I. Epidermolysis Bullosa. In: Rimoin DL, Connor JM, Pyeritz RE, Korf

11 BR, eds. Emery and Rimoin's Principles and Practice of Medical Genetics. Philadelphia:

12 Churchill Livingstone Elsevier 2007:3449-502.

134 Bruckner-Tuderman L, Niemi KM, Kero M, Schnyder UW, Reunala T. Type VII collagen

14 is expressed but anchoring fibrils are defective in dystrophic epidermolysis bullosa inversa.

15 Br J Dermatol 1990;122:383-90.

165 Bruckner-Tuderman L, Winberg JO, Anton-Lamprecht I, Schnyder UW, Gedde-Dahl Jr T.

17 Anchoring fibrils, collagen VII, and neutral metalloproteases in recessive dystrophic

18 epidermolysis bullosa inversa. J Invest Dermatol 1992;99:550-8.

196 Lin AN, Smith LT, Fine JD. Dystrophic epidermolysis bullosa inversa: report of two cases

20 with further correlation between electron microscopic and immunofluorescence studies. J

$21 \quad$ Am Acad Dermatol 1995;33:361-5.

227 Gedde-Dahl Jr T, Winberg JO. Neonatal retention of type VII collagen, transient bullous

23 dermolysis of the newborn and recessive epidermolysis bullosa dystrophica inversa. Br J

24 Dermatol 1994;130:685-6. 
Van den Akker et al.

18 Hovnanian A, Rochat A, Bodemer C, Petit E, Rivers CA, Prost C, Fraitag S, Christiano

2 AM, Uitto J, Lathrop M, Barrandon Y, de Prost Y. Characterization of 18 new mutations

3 in COL7A1 in recessive dystrophic epidermolysis bullosa provides evidence for distinct

4 molecular mechanisms underlying defective anchoring fibril formation. Am J Hum Genet

$5 \quad 1997 ; 61: 599-610$.

69 Gardella R, Castiglia D, Posteraro P, Bernardini S, Zoppi N, Paradisi M, Tadini G, Barlati

7 S, McGrath JA, Zambruno G, Colombi M. Genotype-phenotype correlation in Italian

$8 \quad$ patients with dystrophic epidermolysis bullosa. J Invest Dermatol 2002;119:1456-62.

910 Kern JS, Kohlhase J, Bruckner-Tuderman L, Has C. Expanding the COL7A1 mutation

10 database: novel and recurrent mutations and unusual genotype-phenotype constellations in

1141 patients with dystrophic epidermolysis bullosa. J Invest Dermatol 2006;126:1006-12.

1211 Dang N, Klingberg S, Marr P, Murrell DF. Review of collagen VII sequence variants

13 found in Australasian patients with dystrophic epidermolysis bullosa reveals nine novel

14 COL7A1 variants. J Dermatol Sci 2007;46:169-78.

1512 Varki R, Sadowski S, Uitto J, Pfendner E. Epidermolysis bullosa. II. Type VII collagen

16 mutations and phenotype-genotype correlations in the dystrophic subtypes. J Med Genet

$17 \quad 2007 ; 44: 181-92$.

1813 Kern JS, Gruninger G, Imsak R, Muller ML, Schumann H, Kiritsi D, Emmert S, Borozdin

19 W, Kohlhase J, Bruckner-Tuderman L, Has C. Forty-two novel COL7A1 mutations and

20 the role of a frequent single nucleotide polymorphism in the MMP1 promoter in

21 modulation of disease severity in a large European dystrophic epidermolysis bullosa

22 cohort. Br J Dermatol 2009;161:1089-97.

2314 Van den Akker PC, van Essen AJ, Kraak MMJ, Meijer R, Nijenhuis M, Meijer G, Hofstra

24 RMW, Pas HH, Scheffer H, Jonkman MF. Long-term follow-up of patients with recessive 
Van den Akker et al.

1 dystrophic epidermolysis bullosa in the Netherlands: expansion of the mutation database

2 and unusual phenotype-genotype correlations. J Dermatol Sci 2009;56:9-18.

315 Escámez MJ, Garcia M, Cuadrado-Corrales N, Llames SG, Charlesworth A, De Luca N,

4 Illera N, Sanchez-Jimeno C, Holguin A, Duarte B, Trujillo-Tiebas MJ, Vicario JL,

5 Santiago JL, Hernandez-Martin A, Torrelo A, Castiglia D, Ayuso C, Larcher F, Jorcano

6 JL, Meana A, Meneguzzi G, Zambruno G, Del Rio M. The first COL7A1 mutation survey

7 in a large Spanish dystrophic epidermolysis bullosa cohort: c.6527insC disclosed as an

8 unusually recurrent mutation. Br J Dermatol 2010;163:155-61.

916 Jerabkova B, Kopeckova L, Buckova H, Vesely K, Valickova J, Fajkusova L. Analysis of

10 the COL7A1 gene in Czech patients with dystrophic epidermolysis bullosa reveals novel

11 and recurrent mutations. J Dermatol Sci 2010;59:136-40.

1217 Jonkman MF, de Jong MC, Heeres K, Sonnenberg A. Expression of integrin alpha 6 beta

134 in junctional epidermolysis bullosa. J Invest Dermatol 1992;99:489-96.

1418 Groves RW, Liu L, Dopping-Hepenstal PJ, Markus HS, Lovell PA, Ozoemena L, Lai-

15 Cheong JE, Gawler J, Owaribe K, Hashimoto T, Mellerio JE, Mee JB, McGrath JA. A

16 homozygous nonsense mutation within the dystonin gene coding for the coiled-coil

17 domain of the epithelial isoform of BPAG1 underlies a new subtype of autosomal

18 recessive epidermolysis bullosa simplex. J Invest Dermatol 2010;130:1551-7.

1919 Van den Akker PC, Hettema W, Meijer R, Jonkman MF, Hofstra RM, Scheffer H. Design

20 and validation of a conformation-sensitive capillary electrophoresis system for mutation

21 identification of the COL7A1 gene with automated peak comparison. Genet Test Mol

$22 \quad$ Biomarkers 2009;13:589-97.

20 Bruckner-Tuderman L. Hereditary skin diseases of anchoring fibrils. J Dermatol Sci

$24 \quad$ 1999;20:122-33. 
Van den Akker et al.

121 Mecklenbeck S, Hammami-Hauasli N, Hopfner B, Schumann H, Kramer A, Kuster W,

2 Bruckner-Tuderman L. Clustering of COL7A1 mutations in exon 73: implications for

3 mutation analysis in dystrophic epidermolysis bullosa. J Invest Dermatol 1999;112:398-

$4 \quad 400$.

522 Pulkkinen L, Uitto J. Mutation analysis and molecular genetics of epidermolysis bullosa.

$6 \quad$ Matrix Biol 1999;18:29-42.

723 Zimmer KP, Schumann H, Mecklenbeck S, Bruckner-Tuderman L. Esophageal stenosis in

8 childhood: dystrophic epidermolysis bullosa without skin blistering due to collagen VII

9 mutations. Gastroenterology 2002;122:220-5.

24 Kahofer P, Bruckner-Tuderman L, Metze D, Lemmink H, Scheffer H, Smolle J. Dystrophic epidermolysis bullosa inversa with COL7A1 mutations and absence of GDA-

25 Wong T, Liu L, Ozoemena L, Wessagowit V, Fassihi H, Dopping-Hepenstal PJ, Jones C, Mellerio JE, McGrath JA. Pathogenic nonglycine substitution missense mutations in the type VII collagen triple helix: implications for genotype-phenotype correlation in recessive dystrophic epidermolysis bullosa [abstract]. Br J Dermatol 2006;155 (suppl 1):P28.

26 Chiaverini C, Charlesworth AV, Youssef M, Cuny JF, Rabia SH, Lacour JP, Meneguzzi G. Inversa Dystrophic Epidermolysis Bullosa Is Caused by Missense Mutations at Specific Positions of the Collagenic Domain of Collagen Type VII. J Invest Dermatol. Published Online First: 17 June 2010. doi:10.1038/jid.2010.159.

27 Christiano AM, Amano S, Eichenfield LF, Burgeson RE, Uitto J. Premature termination codon mutations in the type VII collagen gene in recessive dystrophic epidermolysis bullosa result in nonsense-mediated mRNA decay and absence of functional protein. $\mathrm{J}$ Invest Dermatol 1997;109:390-4. 
Van den Akker et al.

128 Dang N, Murrell DF. Mutation analysis and characterization of COL7A1 mutations in

2 dystrophic epidermolysis bullosa. Exp Dermatol 2008;17:553-68.

329 Kon A, Pulkkinen L, Ishida-Yamamoto A, Hashimoto I, Uitto J. Novel COL7A1

4 mutations in dystrophic forms of epidermolysis bullosa. J Invest Dermatol 1998;111:534-

57.

630 Terracina M, Posteraro P, Schubert M, Sonego G, Atzori F, Zambruno G, Bruckner-

7 Tuderman L, Castiglia D. Compound heterozygosity for a recessive glycine substitution

8 and a splice site mutation in the COL7A1 gene causes an unusually mild form of localized

9 recessive dystrophic epidermolysis bullosa. J Invest Dermatol 1998;111:744-50.

35 Christiano AM, Greenspan DS, Lee S, Uitto J. Cloning of human type VII collagen.

31 Suzuki S, Shimomura Y, Yamamoto Y, Kariya N, Shibuya M, Ito M, Fujiwara H. A case of recessive dystrophic epidermolysis bullosa caused by compound heterozygous mutations in the COL7A1 gene. Br J Dermatol 2006;155:838-40.

32 Schumann H, Has C, Kohlhase J, Bruckner-Tuderman L. Dystrophic epidermolysis bullosa pruriginosa is not associated with frequent FLG gene mutations. Br J Dermatol 2008;159:464-9.

33 Riedl E, Klausegger A, Bauer JW, Foedinger D, Kittler H. A novel glycine mutation in the COL7A1 gene leading to dominant dystrophic epidermolysis bullosa with intrafamilial phenotypical heterogeneity. Pediatr Dermatol 2009;26:115-7.

34 Almaani N, Liu L, Harrison N, Tanaka A, Lai-Cheong J, Mellerio JE, McGrath JA. New glycine substitution mutations in type VII collagen underlying epidermolysis bullosa pruriginosa but the phenotype is not explained by a common polymorphism in the matrix metalloproteinase-1 gene promoter. Acta Derm Venereol 2009;89:6-11. Complete primary sequence of the alpha 1 (VII) chain and identification of intragenic polymorphisms. J Biol Chem 1994;269:20256-62. 
Van den Akker et al.

136 Csikos M, Szocs HI, Laszik A, Mecklenbeck S, Horvath A, Karpati S, Bruckner-

2 Tuderman L. High frequency of the 425A--> G splice-site mutation and novel mutations of

3 the COL7A1 gene in central Europe: significance for future mutation detection strategies

4 in dystrophic epidermolysis bullosa. Br J Dermatol 2005;152:879-86.

537 Gedde-Dahl Jr T. The childhood course of recessive epidermolysis bullosa dystrophica

6 inversa. In: Priestley GC, Tidman MJ, Weiss JB, Eady RAJ, eds. Epidermolysis bullosa:

7 A comprehensive review of classification, management and laboratory studies.

8 Crowthorne, Berkshire, UK: DEBRA, UK 1990:84-6.

938 Persikov AV, Pillitteri RJ, Amin P, Schwarze U, Byers PH, Brodsky B. Stability related

10 bias in residues replacing glycines within the collagen triple helix (Gly-Xaa-Yaa) in

11 inherited connective tissue disorders. Hum Mutat 2004;24:330-7.

39 Fritsch A, Spassov S, Elfert S, Schlosser A, Gache Y, Meneguzzi G, Bruckner-Tuderman

40 Herry CL, Frize M. Quantitative assessment of pain-related thermal dysfunction through clinical digital infrared thermal imaging. Biomed Eng Online 2004;3:19.

41 Oji V, Hautier JM, Ahvazi B, Hausser I, Aufenvenne K, Walker T, Seller N, Steijlen PM, Kuster W, Hovnanian A, Hennies HC, Traupe H. Bathing suit ichthyosis is caused by transglutaminase-1 deficiency: evidence for a temperature-sensitive phenotype. Hum Mol Genet 2006;15:3083-97.

42 Vaisanen L, Has C, Franzke C, Hurskainen T, Tuomi ML, Bruckner-Tuderman L, Tasanen K. Molecular mechanisms of junctional epidermolysis bullosa: Col 15 domain mutations decrease the thermal stability of collagen XVII. J Invest Dermatol $2005 ; 125: 1112-8$. 
Van den Akker et al.

143 Aufenvenne K, Oji V, Walker T, Becker-Pauly C, Hennies HC, Stocker W, Traupe H.

2 Transglutaminase-1 and bathing suit ichthyosis: molecular analysis of gene/environment

3 interactions. J Invest Dermatol 2009;129:2068-71.

444 Hackett BC, Fitzgerald D, Watson RM, Hol FA, Irvine AD. Genotype-phenotype

5 correlations with TGM1: clustering of mutations in the bathing suit ichthyosis and self-

6 healing collodion baby variants of lamellar ichthyosis. Br J Dermatol 2010;162:448-51.

745 Berson JF, Frank DW, Calvo PA, Bieler BM, Marks MS. A common temperature-

8 sensitive allelic form of human tyrosinase is retained in the endoplasmic reticulum at the

9 nonpermissive temperature. J Biol Chem 2000;275:12281-9.

1046 Florell SR, Meyer LJ, Boucher KM, Porter-Gill PA, Hart M, Erickson J, Cannon-Albright

11 LA, Pershing LK, Harris RM, Samlowski WE, Zone JJ, Leachman SA. Longitudinal

12 assessment of the nevus phenotype in a melanoma kindred. J Invest Dermatol

$13 \quad 2004 ; 123: 576-82$. 
Van den Akker et al.

\section{FIGURE LEGENDS}

2

3 Figure 1. Clinical features of patients with RDEB-inversa.

4 Typical distribution of skin blistering in RDEB-I patients in the proximal body flexures and

5 body axis with nail dystrophy and involvement of the mucosal membranes. Skin blistering

6 and erosions in (A) the neck of patient 9, (B) the left axilla of patient 17, (C) the lower back in

7 patient 3, and (D) the groins and lower abdomen in patient 6. (E and F) The hands and feet of

8 patient 7 show absent and dystrophic nails, with no completely normal nails. There is no

9 current blistering, but small scars indicate past blistering. (G) Microstomia, ankyloglossia and

10 dental decay of the lower dentition (upper dentition has been repaired) in patient 17 . Written

11 consent was obtained for publication of all images.

\section{Figure 2. Arginine and glycine substitutions associated with RDEB-I.}

14 Schematic representation of the triple-helix domain of type VII collagen. White boxes are 15 collagenous subdomains COL1-20, black bars represent collagenous imperfections IM1-19, and the hinge region (IM10) is hatched. The glycine substitutions are shown above the triple-

17 helix domain, and the arginine substitutions below. All known arginine and glycine substitutions, as summarized by Dang and Murrell,[28] are shown. Glycine and arginine substitutions associated with RDEB-I are depicted above and below the dashed lines,

20 respectively. Glycine and arginine substitutions exclusively reported in RDEB-I are shown in 21 bold. Novel glycine substitutions are shown in italics.

\section{Figure 3. Digital thermographs of a healthy human body.}

24 Photos obtained by digital infrared thermal imaging of (A) front and (B) back of a healthy

25 female human body showing higher body temperatures in the typical inversa body sites, i.e. 
Van den Akker et al.

1 the proximal flexures, neck, lower back and submammary folds, compared to more distal

2 body parts. The colour scales indicate the temperatures that correspond to the colours used in

3 the images. Images published with permission from Meditherm Inc, Hilversum, the

4 Netherlands. 


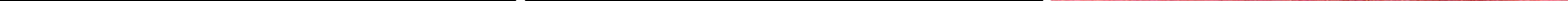


Noninversa

Noninversa $\mathrm{R} 1538 \mathrm{H}$
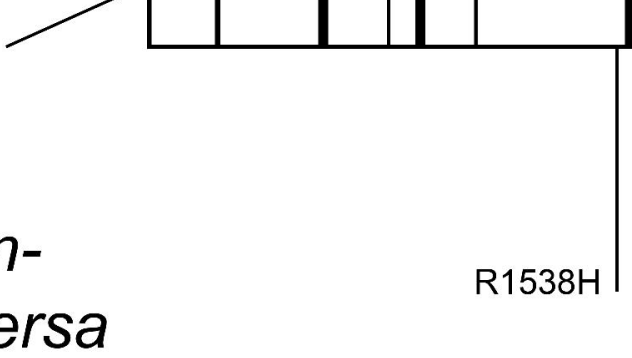

G1664A G1719R

G1347R

G1338V

G'1557R

G1522R

G1519D

G1492R

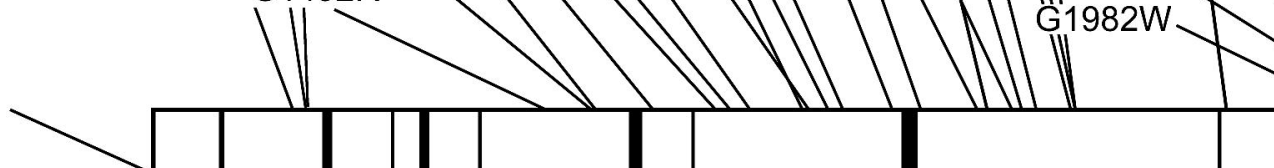

G2034W G2040D T2031S G2034R G2040V /G2055E G2028A G2034E I / G2064R G2028R G2025S G2037EG2043R G2064E G2025A G2043W G2067R G2015E G2012D V G1812R G1791E G1782V

G2009R

G2073D

G2006A

G2006D

G2003R
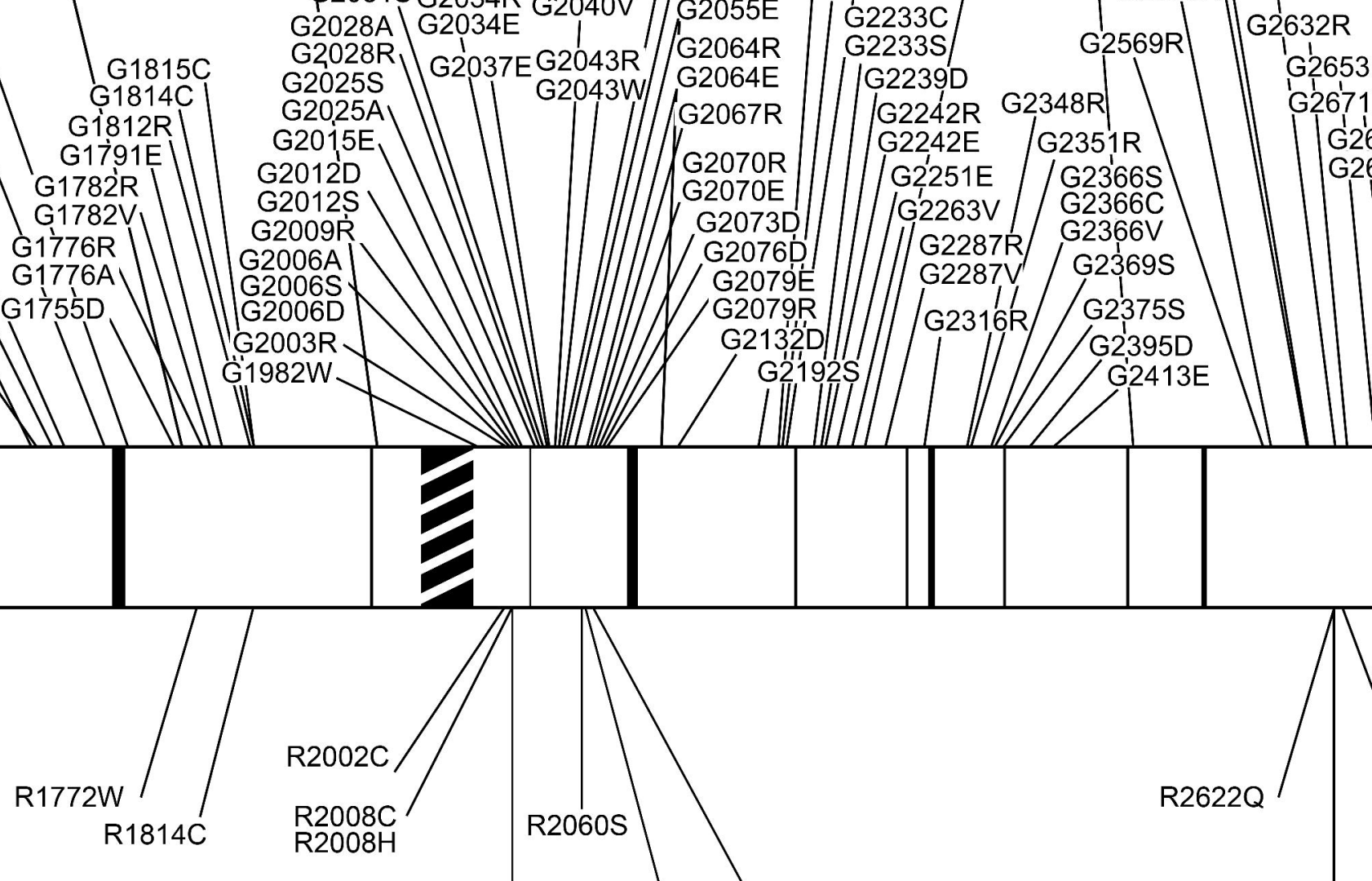

G2713D G2719R G2719D $/ / \mathrm{G} 2737 \mathrm{R}$ / G2079E $/$ G207//G2287R/G / G2369S G2132'D G2316R G2375S G2192S

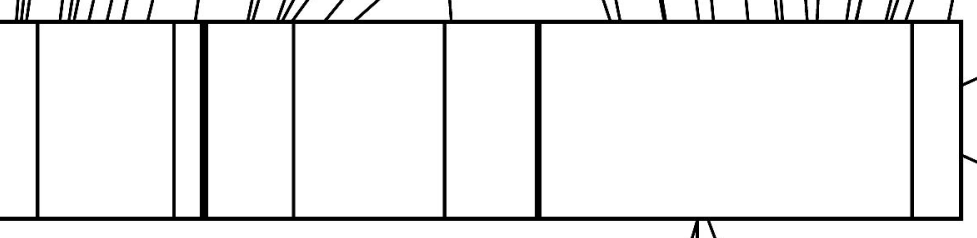

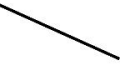




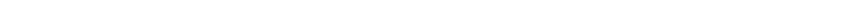

